\title{
A comparative study between the efficacy of local intra-myometrial injection of vasopressin and octreotide acetate, in reducing blood loss during myomectomy
}

\author{
Amira Mohammed Badawy*
}

Department of Obstetrics and Gynecology, Faculty of Medicine, Alexandria University, Egypt

Received: 17 July 2017

Accepted: 18 August 2017

\section{*Correspondence:}

Dr. Amira Mohammed Badawy,

E-mail: dr.amirabadawy@gmail.com

Copyright: () the author(s), publisher and licensee Medip Academy. This is an open-access article distributed under the terms of the Creative Commons Attribution Non-Commercial License, which permits unrestricted non-commercial use, distribution, and reproduction in any medium, provided the original work is properly cited.

\section{ABSTRACT}

Background: Symptomatic Uterine leiomyomata may lead to many symptoms including abnormal uterine bleeding, mass pressure effects and infertility. Myomectomy is an option for conservative management, however, it is associated with some disadvantages, mainly increased intra-operative blood loss. Intra-myometrial vasopressin injection during myomectomy is an effective method to decrease the intraoperative bleeding due to its vasoconstrictor effect. Octreotide Acetate (OA) is another vasoconstrictor agent that have not been tested for gynaecologic indications. The current study was conducted to assess the efficacy of local injection of OA in reducing blood loss during conventional abdominal myomectomy, and to compare it with local instillation of vasopressin.

Methods: 60 cases with symptomatic leiomyomata were recruited and planned for abdominal myomectomy, they were divided randomly into 3 groups, 20 cases in each. Group I, where local vasopressin was used, group II, where OA was used, and group III (the control group), where no specific medication was used and only free Saline was injected locally.

Results: The overall results showed that OA group had significantly less operative time and less blood loss compared to control group. However, when compared to cases in group I, operative time and blood loss were significantly higher. Postoperative haemoglobin levels were significantly lower in group III compared to groups I $(P=0.039)$ and II $(\mathrm{P}=0.044)$. Blood transfusion was indicated in 9 cases among group III, while only one case needed blood transfusion in group II, and no cases in group I.

Conclusions: The use of local intra-myometrial OA is an option for reducing blood loss during myomectomy, but still efficacy is less than local vasopressin. This may be attributed to the low concentrations used, and to the less potency of $\mathrm{OA}$ as a vasoconstrictor agent.

Keywords: Leiomyomata, Myomectomy, Octreotide Acetate, Uterine fibroids, Vasopressin

\section{INTRODUCTION}

Uterine myomata are the most frequent tumours of the female genital tract affecting 20-50\% of all women, with an increased incidence in the later years of a woman's reproductive life. ${ }^{1}$ Myoma is mostly asymptomatic. Size and location are the main factors that determine if a myoma leads to symptoms and problems. Important symptoms include abnormal uterine bleeding, abdominal discomfort, bloating, painful defecation, backache, urinary frequency or retention and infertility. It is associated with impairment of Health-Related Quality of Life (HRQOL). ${ }^{2}$ Patients have multiple options in the management of uterine myomas including observation, 
medical therapy, uterine artery embolization, high intensity focused ultrasound ablation and as well as surgical methods like myomectomy and hysterectomy. Surgical removal is necessary when the myoma is symptomatic and resistant to medical management or interferes with reproduction. Although uterine artery embolization is now an effective way for managing symptomatic uterine myomas but its effect on future conception remains unclear. ${ }^{3}$

Myomectomy is an invasive surgical procedure, may be performed abdominally, laparoscopically or by robotic method. It can be associated with many intraoperative and postoperative complications including excessive haemorrhage, pyrexia, visceral damage, thromboembolism, conversion to hysterectomy, blood transfusions, scar dehiscence in future pregnancy and many others. ${ }^{4}$

There are various pharmacological and nonpharmacological methods have been tested to control haemorrhage during myomectomy. At present, there is moderate-quality evidence that misoprostol or vasopressin may reduce bleeding during myomectomy, and low-quality evidence that bupivacaine plus epinephrine, tranexamic acid, gelatin-thrombin matrix, ascorbic acid, dinoprostone, loop ligation, fibrin sealant patches, peri-cervical tourniquet, or tourniquet tied around both cervix and infundibulopelvic ligaments may reduce bleeding during myomectomy. There is no evidence that oxytocin, morcellation or temporary clipping of the uterine artery reduce blood loss. ${ }^{5}$

Intra-myometrial vasopressin injection during myomectomy operation may effectively decrease the intraoperative blood loss, need for blood transfusion, and causes less reduction in haemoglobin and haematocrit in postoperative period. It also eliminates the risk of unwanted irreversible ischemic damage to the uterus and thrombo-embolic events of mechanical methods. ${ }^{6,7}$ On the other hand, and because it is a potent systemic vasoconstrictor, vasopressin may cause hypertension and bradycardia. It has a plasma half-life of 10-20 minutes. Care should be taken to infiltrate a dilute solution with hemodynamic monitoring. To avoid unwanted surges in blood pressure. The anti-diuretic activity of vasopressin can last for two to eight hours. This can be easily reversed with an intravenous diuretic like Frusemide. ${ }^{8}$

In our country and other developing countries, vasopressin is not routinely used during conventional myomectomy due to non-availability and high cost, and therefore other less effective methods are used to reduce bleeding during open or laparoscopic myomectomy.

Octreotide Acetate (OA) (Sandostatine ${ }^{\circledR}$ ), is an octapeptide that mimics natural somatostatin pharmacologically. It is commonly used as an adjuvant agent in the management of variceal bleeding. The mechanism of action of octreotide in portal hypertension is not fully understood. ${ }^{9}$

In vivo, human studies have shown that OA has direct effects on vascular smooth muscle and in veins leading to vasoconstriction. ${ }^{10}$ It was also concluded that $\mathrm{OA}$ has a local arterial vasoconstrictive effect in patients with cirrhosis that is independent of systemic hormonal modulation of glucagon, this vasomotor action seems to be independent of Nitric Oxide. ${ }^{11}$

Based on these data, the current study was performed, to test the local vasoconstrictive effect of OA in reducing blood loss during conventional myomectomy, and to compare it to local injection of vasopressin.

The current study was conducted to assess the efficacy of local injection of $\mathrm{OA}$ in reducing blood loss during conventional abdominal myomectomy, and to compare it with local instillation of vasopressin.

\section{METHODS}

This study is a prospective double blind randomised controlled study. It was conducted between March 2016, and February 2017. The study was done after taking the permission from the local ethical committee in accordance with the ethical standards of the responsible committee on human experimentation (institutional) and with the Helsinki Declaration of 1975 that was revised in $2000 .^{12}$

\section{Patient selection and Study design}

Total number of 60 women were recruited $\&$ planned for myomectomy. Inclusion criteria were women of reproductive age group, having symptomatic myomata not responding to medical therapy and refusing hysterectomy or not completed their family size, with total uterine size not exceeding 18 weeks, total number of myomata (diagnosed sonographically) 1-5, and myoma grades $2,3,4,5$, and/or 6 .

Exclusion criteria were low haemoglobin level $(<10$ $\mathrm{mg} / \mathrm{dl}$ ), concomitant adenomyosis, cervical or pedunculated myomata, bleeding diathesis, prior GnRH-a medication, cases unfit for surgery or anaesthesia, and cases where vasopressin, or OA are contraindicated.

Cases were equally divided into 3 groups, 20 cases in each. In the first group (group A), vasopressin was used. In the second group (group B) OA was used, while the third group (group C) was the control one, where no specific medication was used to reduce myomectomy bleeding.

After admission and history taking, informed written consents were taken from all participants. Cases were subjected to transvaginal and transabdominal ultrasound 
to determine the number, size, and site of myomata, and to exclude adenomyosis and other pelvic pathology.

The total uterine volume was calculated using the formula (Volume $=0.52 \times \mathrm{h} \times \mathrm{d} \times \mathrm{w})$, where $(\mathrm{h}),(\mathrm{d}),(\mathrm{w})$ are the maximum uterine dimensions in the three orientations (height, depth, and width respectively) assuming the uterus to have an ellipsoid shape. The volume of the leading myoma was also calculated using the formula (Volume $=4 / 6 \pi \times$ a $\times$ b x c) where (a), (b), and (c) are the three dimensions of the fibroid determined on two orthogonal ultrasound views respectively, assuming the fibroid to be a sphere.

Preoperative laboratory tests were done (including complete blood picture, blood sugar profile, liver and renal function tests, hepatitis screen and coagulation profile).

\section{Procedures}

All cases were subjected to laparotomy via mid-line, or (mostly) Pfannenstiel incision. Before incision over any myoma, and after informing the anaesthesia team, local injection (at the myoma-myometrial junction) was performed, using either:

- Ampule Vasopressin (Pitressin ${ }^{\circledR}$-APP Pharmaceuticals) $20 \mathrm{IU}$ ( $1 \mathrm{ml})$ diluted in $20 \mathrm{ml}$ saline (in a dilution of 1:20), in group I,

- Ampules Octreotide Acetate (Sandostatin ${ }^{\circledR}$-Novartis Pharmaceuticals) $0.050 \mathrm{mg}(1 \mathrm{ml})$ diluted in $20 \mathrm{ml}$ saline (in a dilution of $1: 10$ ), in group II.

- $20 \mathrm{ml}$ normal Saline (free of any medication), in group III.

Cases were randomly selected and allocated to the three groups. Two surgeons of similar qualification and experience performed all myomectomies. The operating surgeon was not informed about the nature of the injected medication.

The total volume of medication injected (Vasopressin, $\mathrm{OA}$, or Saline) varied depending on the number and size of myomata to be removed.

Prior injecting the medication, negative suction by the injecting syringe was performed to avoid intra-vascular instillation of the drug. Then incision over the myoma started 1-3 minutes after medication injection \& no other methods were used to reduce bleeding (either pre- or intra-operative).

\section{Outcomes}

Intra-operative blood loss was estimated by adding the volume in the suction container after completion of each procedure with the estimated blood loss from weighing of the soaked laparotomy mop packs which were placed dry in the abdomen after opening the parietal peritoneum.
Operative time and complications were also registered. Postoperative parameters included haemoglobin values (on day two uniformly), need for blood transfusion and other complications were also tabulated. Blood transfusion (if needed) was done after estimation of the post-operative haemoglobin level.

\section{Statistical analysis}

The Data were collected and fed to the computer. Statistical analysis was performed using IBM Statistical Package for Social Sciences (SPSS/version 20.0) software.

Quantitative data were described using mean and standard deviation for normally distributed data, while abnormally distributed data were expressed using median, minimum, and maximum. The distribution of quantitative variables was tested for normality using Kolmogorov-Smirnov test, Shapiro-Wilk test, and D'Agstino tests. If it reveals normal data distribution, parametric tests were applied. If the data were abnormally distributed, non-parametric tests were used. For normally distributed data, comparison between two independent population were done using independent t-test, while for abnormally distributed data, comparison was done using Mann Whitney and Wilcoxon signed ranks test to compare between pre, and post. Significance of the obtained results was judged at the 0.05 level.

\section{RESULTS}

A total of 60 women were enrolled in this trial with an even distribution between the three groups. Baseline characteristics of study participants are summarised in Table 1. There were no differences regarding age, parity, or body mass index (BMI), $(\mathrm{p}>0.05)$.

As shown in Table 2, most of the recruited cases listed abnormal uterine bleeding, pain and/or sense of heaviness as the main complaint(s).

Others reported feeling of abdominal mass or subfertility. However, the fibroids were discovered accidentally in a small number of cases (7 cases, 11.6\%).

Pre-operative total uterine volume and the leading (biggest) myoma volume were calculated, Table 3 shows that volumes were comparable between the three studied groups.

All patients were subjected to conventional myomectomy, using either Pfannenstiel or sub-umbilical midline incisions according to the uterine and myoma size. The total operative time was calculated, and it was highly significantly longer in group III $(105.5+17.46$ minutes) compared to the other two groups. There was also a significant increased operative time in group II (81.75 \pm 16.16 minutes) when compared to group I (59 \pm 15.69 minutes) (Table 4). 
Table 1: Characteristic feature of the studied patients' groups.

\begin{tabular}{|c|c|c|c|c|}
\hline & Group I (Vasopressin) $\mathbf{n}=\mathbf{2 0}$ & Group II (OA) n = 20 & Group III (free Saline) $\mathbf{n}=\mathbf{2 0}$ & $\begin{array}{l}\text { Anova } \\
\text { P Value }\end{array}$ \\
\hline \multicolumn{5}{|l|}{ Age } \\
\hline Range & $32-50$ & $23-49$ & $21-48$ & 0.551 \\
\hline Mean \pm S.D & $39.4 \pm 5.7$ & $37.9 \pm 7.45$ & $37.2 \pm 7.04$ & 0.579 \\
\hline \multicolumn{5}{|l|}{ Parity } \\
\hline Range & $0-7$ & $0-5$ & $0-7$ & 1.301 \\
\hline Mean \pm S.D & $2.75 \pm 2.17$ & $1.85 \pm 1.66$ & $1.95 \pm 1.93$ & 0.280 \\
\hline \multicolumn{5}{|l|}{ BMI } \\
\hline Range & $26.04-37.65$ & $22.77-37.83$ & $23.34-37.83$ & 0.629 \\
\hline Mean \pm S.D & $31.72 \pm 4.15$ & $30.32 \pm 4.04$ & $30.92 \pm 3.69$ & 0.537 \\
\hline
\end{tabular}

$\mathrm{OA}=$ Octreotide Acetate, $\mathrm{BMI}=$ body mass index.

Table 2: Comparison between the three studied groups regarding complaints showed that there was no significant difference.

\begin{tabular}{|c|c|c|c|c|c|c|c|}
\hline & \multicolumn{2}{|c|}{$\begin{array}{l}\text { Group I } \\
(\text { Vasopressin) } \mathbf{n}=\mathbf{2 0}\end{array}$} & \multicolumn{2}{|c|}{$\begin{array}{l}\text { Group II } \\
(\text { OA }) n=20\end{array}$} & \multicolumn{2}{|c|}{$\begin{array}{l}\text { Group III } \\
\text { (free Saline) } n=20\end{array}$} & \multirow[t]{2}{*}{ P Value } \\
\hline & No. & $\%$ & No. & $\%$ & No. & $\%$ & \\
\hline Abnormal uterine bleeding & 13 & 65.0 & 11 & 55.0 & 12 & 60.0 & 0.812 \\
\hline Mass felt in the abdomen & 9 & 45.0 & 8 & 40.0 & 8 & 40.0 & 0.934 \\
\hline Pain and/or Sense of heaviness & 13 & 65.0 & 12 & 60.0 & 9 & 45.0 & 0.414 \\
\hline Sub-fertility & 5 & 25.0 & 4 & 20.0 & 2 & 10.0 & 0.459 \\
\hline Accidental discovery & 1 & 5.0 & 3 & 15.0 & 3 & 15.0 & 0.524 \\
\hline
\end{tabular}

Table 3: Total uterine volume and leading myoma volume of the studied patients group, there was no significant difference between the three groups $(p>0.05)$.

\begin{tabular}{|c|c|c|c|c|}
\hline & $\begin{array}{l}\text { Group I } \\
\text { (Vasopressin) } n=\mathbf{2 0}\end{array}$ & $\begin{array}{l}\text { Group II } \\
(\text { OA) } n=20\end{array}$ & $\begin{array}{l}\text { Group III } \\
\text { (free Saline) } n=20\end{array}$ & P Value \\
\hline \multicolumn{5}{|c|}{ Total uterine volume } \\
\hline Range & $389.1-14027.4$ & $434.7-1561.2$ & $404.0-1480.0$ & 0.983 \\
\hline Mean \pm S.D & $1574.2 \pm 2947.3$ & $924.3 \pm 303.6$ & $902.8 \pm 327.7$ & 0.380 \\
\hline \multicolumn{5}{|c|}{ Leading myoma volume } \\
\hline Range & $199.2-1109.3$ & $187.9-1122.2$ & $237.8-1121.1$ & 0.019 \\
\hline Mean \pm S.D & $623.35 \pm 317.38$ & $642.76 \pm 341.04$ & $636.98 \pm 313.7$ & 0.981 \\
\hline
\end{tabular}

Table 4: Operative data in the three-studied group.

\begin{tabular}{|c|c|c|c|c|}
\hline & $\begin{array}{l}\text { Group I } \\
(\text { Vasopressin) } n=\mathbf{2 0}\end{array}$ & $\begin{array}{l}\text { Group II } \\
(\text { OA }) n=20\end{array}$ & $\begin{array}{l}\text { Group III } \\
\text { (free Saline) } n=20\end{array}$ & P Value \\
\hline \multicolumn{5}{|c|}{ Duration of surgery (min.) } \\
\hline Range & $40-95$ & $50-110$ & $70-140$ & 39.921 \\
\hline Mean \pm S.D & $59 \pm 15.69$ & $81.75 \pm 16.16$ & $105.5 \pm 17.46$ & $0.0001 * *$ \\
\hline P1 & & $0.001 *$ & $0.0001 *$ & \\
\hline $\mathrm{P} 2$ & & & $0.021 *$ & \\
\hline \multicolumn{5}{|c|}{ Estimated blood loss (ml) } \\
\hline Range & $80-220$ & $90-720$ & $390-1090$ & 126.99 \\
\hline Mean \pm S.D & $113 \pm 37.43$ & $279 \pm 148.28$ & $820.5 \pm 203.19$ & $0.0001 * *$ \\
\hline P1 & & $0.001 *$ & $0.0001 *$ & \\
\hline $\mathrm{P} 2$ & & & $0.001 *$ & \\
\hline
\end{tabular}

P1 comparison between group I and both II and III, P2 comparison between group II and III.

Estimated intra-operative blood loss in group III was also highly significant $(820.5 \pm 203.19 \mathrm{ml})$ compared to group I and II, and it was significantly more in group II $(279 \pm 148.28 \mathrm{ml})$ compared to group I $(113 \pm 37.43 \mathrm{ml})$
(Table 4) (Figure 1). Preoperative and postoperative haemoglobin levels were recorded, and the change was calculated. Pre-operative level of haemoglobin was comparable in the three groups as no cases were operated 
upon except after correction of haemoglobin level to reach at least $10 \mathrm{mg} / \mathrm{dl}$. The reduction in haemoglobin level after operation was significant in group III $(p=0.043)$, while it was not significant between the two other groups.

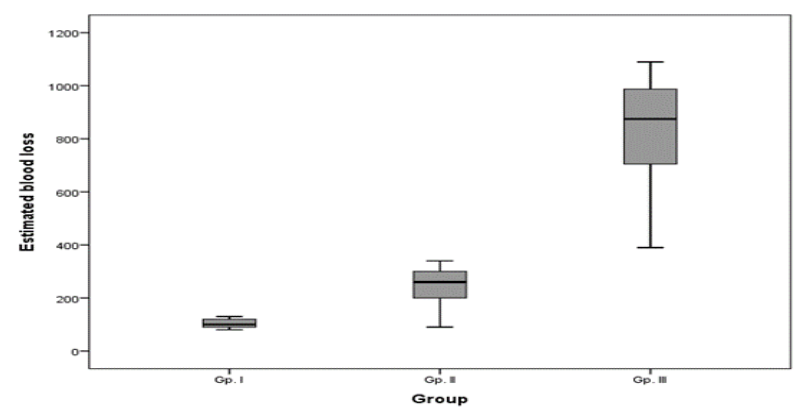

Figure 1: Box plot graph show the amount of estimated blood loss in the three groups.

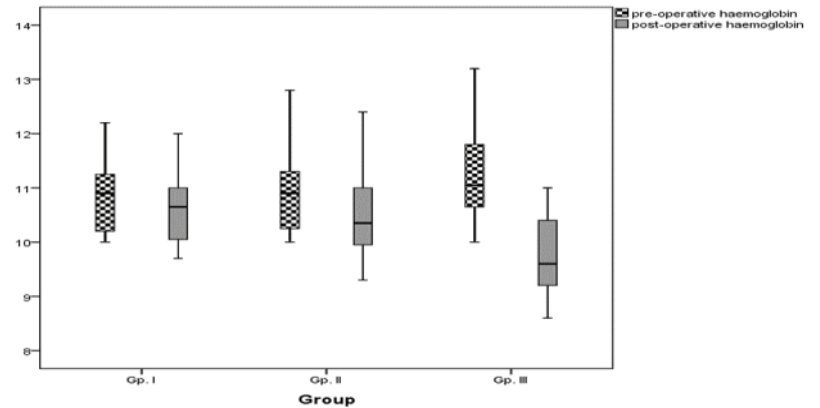

Figure 2: Box plot graph show the haemoglobin level pre- and post-operate in the three studied groups.

And the level of postoperative haemoglobin was significantly lower in group III when compared to groups I ( $\mathrm{p}=0.039)$ and II ( $\mathrm{p}=0.044)$, (Table-5) (Figure 2). Blood transfusion was more indicated among women in group III (9 cases, 45\%), compared to one case in group II $(5 \%)$, and no cases in group I (Table 6).

Table 5: Comparison between pre- and post-operative haemoglobin level in the three studied groups.

\begin{tabular}{|c|c|c|c|c|}
\hline & $\begin{array}{l}\text { Group I } \\
\text { (Vasopressin) } n=20\end{array}$ & $\begin{array}{l}\text { Group II } \\
(\text { OA) } n=20\end{array}$ & $\begin{array}{l}\text { Group III } \\
\text { (free Saline) } n=20\end{array}$ & P1 \\
\hline \multicolumn{5}{|c|}{ Pre-operative haemoglobin (mg/dl) } \\
\hline Range & $10-13$ & $10-12.8$ & $10-13.2$ & 1.001 \\
\hline Mean \pm S.D & $10.93 \pm 0.83$ & $10.91 \pm 0.72$ & $11.23 \pm 0.84$ & 0.374 \\
\hline \multicolumn{5}{|c|}{ Post-operative haemoglobin (mg/dl) } \\
\hline Range & $9.7-12.7$ & $9.3-12.4$ & $8.6-11.0$ & 8.11 \\
\hline Mean \pm S.D & $10.75 \pm 0.82$ & $10.5 \pm 0.79$ & $9.79 \pm 0.715$ & $0.001 *$ \\
\hline $\mathrm{P} 2$ & 0.369 & 0.422 & $0.043 *$ & \\
\hline P3 & & 0.401 & $0.039 *$ & \\
\hline $\mathrm{P} 4$ & & & $0.044 *$ & \\
\hline
\end{tabular}

P1 comparison between the three groups at the same time. P2 comparison between pre- and post-operative at the same group. P3 comparison between group I and both II and III postoperatively. P4 comparison between group II and III post operatively.

Table 6: Comparison between the three studied groups regarding the need for blood transfusion.

\begin{tabular}{|c|c|c|c|c|c|c|}
\hline & \multicolumn{2}{|c|}{$\begin{array}{l}\text { Group I (Vasopressin) } \\
\mathbf{n}=\mathbf{2 0}\end{array}$} & \multicolumn{2}{|c|}{$\begin{array}{l}\text { Group II (OA) } \\
n=20\end{array}$} & \multicolumn{2}{|c|}{$\begin{array}{l}\text { Group III (free Saline) } \\
\mathrm{n}=20\end{array}$} \\
\hline & No. & $\%$ & No. & $\%$ & No. & $\%$ \\
\hline Need for blood transfusion & 0 & 0.0 & 1 & 5.0 & 9 & 45.0 \\
\hline $\mathrm{P}$ & \multicolumn{6}{|c|}{$0.0001 * *$} \\
\hline $\mathrm{P} 1$ & & & \multirow{2}{*}{\multicolumn{2}{|c|}{0.521}} & \multicolumn{2}{|c|}{$0.001 *$} \\
\hline $\mathrm{P} 2$ & & & & & \multicolumn{2}{|c|}{$0.001 *$} \\
\hline
\end{tabular}

P1 comparison between group I and both II and III. P2 comparison between group II and III.

Table 7: comparison between the three studied groups regarding intra-operative complications.

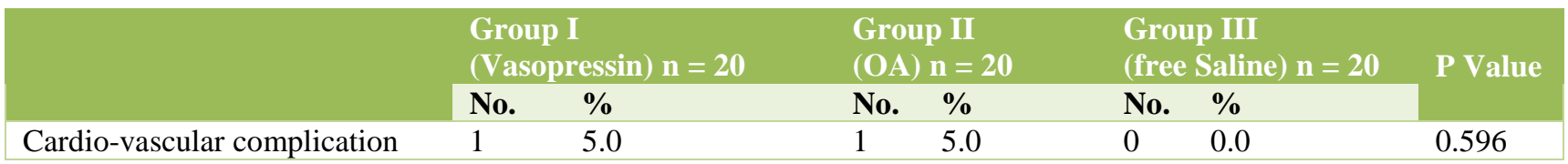


2 cases (one in group I and one in group II) had slight drop in heart rate after local injection of vasopressin and $\mathrm{OA}$, and were immediately controlled by anaesthesia team using parenteral atropine. This complication was not reported among cases of group III (Table 7).

In the current study, major complications like ureteric injury, bladder injury, bowel injury were not encountered in any patient among the three groups. Histopathological examination of the resected tissue showed leiomyomata in all patients and confirmed the diagnosis of uterine myomata.

\section{DISCUSSION}

The local arterial vasoconstrictive effect of OA was previously studied and proved in patients with cirrhosis, but still not utilized in gynaecologic practice. ${ }^{11}$ The current randomized trial is the first one of its type to study the effect of local OA injection as a method of reducing blood loss during myomectomy operation. The current results showed that the use of OA was effective in reducing bleeding during myomectomy, when compared to control cases (placebo group) where no methods were used to reduce bleeding. This was evidenced by the less drop in postoperative haemoglobin level and the less need for blood transfusion. Operative time was significantly lower in OA group as well.

Frederick et al. published the first randomized trial evaluating vasopressin use at time of abdominal myomectomy comparing it with local saline injection as a placebo. Significant differences were seen regarding higher blood loss, greater change in haematocrit and higher rate of blood transfusions in the placebo group..$^{13}$ Similar findings were observed in the current study, as well many other trials. ${ }^{14,15}$

When compared to local vasopressin injection, OA showed less efficacy in reducing blood loss $(113 \pm 37.43$ $\mathrm{ml}$ vs $279 \pm 148.28 \mathrm{ml})$. This may be attributed -in part- to the low concentrations of OA used in the current study. The postoperative reduction in haemoglobin level was also less in Vasopressin group compared to OA group, but difference was not significant. Operative time was therefore more among the OA group $(81.75 \pm 16.16$ vs $59 \pm 15.69)$. However, there was no significant difference in the need for blood transfusion.

Estimated blood loss with vasopressin was variable in different studies, this may be attributed to different concentrations and variable methods of administration. , $^{6,16,17}$

No major operative complications were reported in any case of the current study, but transient intra-operative bradycardia was seen in two cases (one in vasopressin group and another in the OA group), they were immediately managed by intra-venous atropine. Surprisingly, the injected medication volume in these two patients was not high compared to many other cases, where the doses was higher due to more and bigger myomata. In all cases, direct intra-vascular instillation of the vasoconstrictor agent was avoided by pre-injection negative suction by the injecting syringe. Severe form of cardiovascular adverse effects was reported in other studies as a possible complication of local vasopressin use during myomectomy. ${ }^{18,19}$

\section{CONCLUSION}

In conclusion, the current study proofs that the use of local intra-myometrial $\mathrm{OA}$ is to be considered as an option for reducing blood loss during myomectomy, but still efficacy is less than local vasopressin. This may be attributed to the low concentrations used in our study, and the less potency of $\mathrm{OA}$ as a vasoconstrictor agent. Therefore, more studies are to be conducted using higher concentrations of OA to reach the optimum effective dose with the least possible adverse effects.

Funding: No funding sources

Conflict of interest: None declared

Ethical approval: The study was approved by the Institutional Ethics Committee

\section{REFERENCES}

1. Sami Walid M, Heaton RL. The role of laparoscopic myomectomy in the management of uterine fibroids. Curr Opin Obstet Gynecol. 2011;23(4):273-7.

2. Downes E, Sikirica V, Gilabert-Estelles J, Bolge SC, Dodd SL, Maroulis C, et al. The burden of uterine fibroids in five European countries. Eur J Obstet Gynecol Reprod Biol. 2010;152(1):96-102.

3. Kitson SJ, Macphail S, Bulmer J. Is pregnancy safe after uterine artery embolisation? BJOG: An Internat J Obstetr Gynaecol. 2012;119(5):519-21.

4. Paul GP, Naik SA, Madhu KN, Thomas T. Complications of laparoscopic myomectomy: A single surgeon's series of 1001 cases. Australian and New Zealand J Obstetr Gynaecol. 2010;50(4):38590.

5. Kongnyuy EJ, Wiysonge CS. Interventions to reduce haemorrhage during myomectomy for fibroids. Cochrane Database of Systematic Reviews. 2014(8).

6. Saha MM, Khushboo, Biswas SC, Alam H, Kamilya GS, Mukhopadhyay M, et al. Assessment of Blood Loss in Abdominal Myomectomy by Intramyometrial Vasopressin Administration Versus Conventional Tourniquet Application. J Clin Diagn Res. 2016;10(5):QC10-3.

7. Rodriguez-Ayala G, Moses D, Nimaroff M. The Use of Vasopressin to Reduce Blood Loss During Myomectomy. Journal of Minimally Invasive Gynecology. 2016;23(7, Supplement):S149.

8. Sinha M, Chiplonkar S. Anesthesia concerns in laparoscopic myomectomy. J Gynecol Endosc Surg. 2011;2(1):18-20. 
9. Bildozola M. Efficacy of Octreotide and Sclerotherapy in the Treatment of Acute Variceal Bleeding in Cirrhotic Patients: A Prospective, Multicentric, and Randomized Clinical Trial. Scandinavian J Gastroenterol. 2000;35(4):419-25.

10. Dimech J, Feniuk W, Latimer RD, Humphrey PPA. Somatostatin-Induced Contraction of Human Isolated Saphenous Vein Involves sst2 Receptor-Mediated Activation of L-Type Calcium Channels. Journal of Cardiovascular Pharmacology. 1995;26(5):721-8.

11. Chatila R, Ferayorni L, Gupta T, Groszmann RJ. Local arterial vasoconstriction induced by octreotide in patients with cirrhosis. Hepatology. 2000;31(3):572-6.

12. World Medical Association. World Medical Association Declaration of Helsinki: Ethical Principles for Medical Research Involving Human Subjects. JAMA. 2013;310(20):2191-4.

13. Frederick J, Fletcher H, Simeon D, Mullings A, Hardie M. Intramyometrial vasopressin as a haemostatic agent during myomectomy. Br J Obstet Gynaecol. 1994;101(5):435-7.

14. Canseco-Lima JM, Hernandez-Denis A, AudifredSalomon J. Vasopressin Myoma Infiltration During Hysteroscopic Myomectomy. J Minim Invasive Gynecol. 2015;22(6S):S123.

15. Zhao F, Jiao Y, Guo Z, Hou R, Wang M. Evaluation of loop ligation of larger myoma pseudocapsule combined with vasopressin on laparoscopic myomectomy. Fertil Steril. 2011;95(2):762-6.

16. Fletcher H, Frederick J, Hardie M, Simeon D. A randomized comparison of vasopressin and tourniquet as hemostatic agents during myomectomy. Obstet Gynecol. 1996;87(6):1014-8.

17. Cohen SL, Wang KC, Gargiulo AR, Srouji S, Goggins ER, Solnik J, et al. Vasopressin Administration During Laparoscopic Myomectomy: A Randomized Controlled Trial. Journal of Minimally Invasive Gynecology. 2015;22(6, Supplement):S39.

18. Deschamps A, Krishnamurthy S. Absence of pulse and blood pressure following vasopressin injection for myomectomy. Can J Anaesth. 2005;52(5):552-3.

19. Hobo R, Netsu S, Koyasu Y, Tsutsumi O. Bradycardia and cardiac arrest caused by intramyometrial injection of vasopressin during a laparoscopically assisted myomectomy. Obstet Gynecol. 2009;113(2 Pt 2):484-6.

Cite this article as: Badawy AM. A comparative study between the efficacy of local intra-myometrial injection of vasopressin and octreotide acetate, in reducing blood loss during myomectomy. Int $\mathbf{J}$ Reprod Contracept Obstet Gynecol 2017;6:4230-6. 